\title{
Let's Talk About it: Discussing Retirement with Multiple Sources is Associated with Retirement Preparation in Young Adults
}

\author{
Stanislav $\operatorname{Treger}^{1}$ (D) \\ Accepted: 29 June 2021 / Published online: 20 July 2021 \\ (c) The Author(s), under exclusive licence to Springer Science+Business Media, LLC, part of Springer Nature 2021
}

\begin{abstract}
Although young adults are interested in finance, their financial competence, especially about the topic of retirement, is fairly thin. With a large sample of members of Generation Z (ages 18-25, $n=1,311$ ), I explored whether young adults talk about retirement with others; and the correlates between talking about retirement and retirement preparation. Participants reported whether they have spoken about retirement with nine sources: parents, siblings, other family members (non-parent; non-sibling), friends, significant others, co-workers, financial advisors, people on internet forums, and "other sources." All participants reported to have discussed retirement with at least one source, with parents being the most common. Young adults' attitudes towards retirement preparation were largely positive. For example, participants acknowledged the importance of learning about retirement and experienced more positive than negative affect when thinking about retirement. Behavioral measures of retirement preparation did not yield any effects, showing a potential gap between young adults' retirement preparation attitudes and behavior. Multiple regression analyses revealed that the effect of retirement conversations on retirement preparation varied by source. I tie the findings into past research and discuss practical implications.
\end{abstract}

Keywords Behavioral economics $\cdot$ Personal financing $\cdot$ Financial management $\cdot$ Retirement $\cdot$ Decision-making $\cdot$ Young adults

Personal finance can be daunting for young and old alike. With different laws and terms spread across various financial domains, learning about and keeping track of one's finances can be an anxiety-inducing ordeal (Archuleta et al., 2013; Shapiro \& Burchell, 2012). Finance can be especially intimidating for young adults who are either nearing or are experiencing the transition into the workforce, as many have likely had little to no exposure to any formal financial education in their past (e.g., Brown et al., 2016; Kaiser \& Menkhoff, 2019; McCormick, 2009; Sherraden et al., 2011). As a result, young adults may develop a poor understanding of finance (Beck \& Garris, 2019).

Despite poor understanding, young adults appear to acknowledge its importance and show interest in learning about finance (Beck \& Garris, 2019). Still, sources of financial education for young adults appear to be thin. In fact, finance is required in high school curricula in only 21 states as of 2020, although this number is growing (Council

Stanislav Treger

stan.treger@morningstar.com

1 Morningstar, Inc., Chicago, IL, USA for Economic Education, 2020). Intuition may lead one to believe that simple financial education can prepare young adults to be cognizant consumers. Research on the effects of financial education, however, has demonstrated that interventions aimed to improve financial literacy produce small to negligible effects ${ }^{1}$ (Kaiser \& Menkhoff, 2019; Kaiser et al., 2020; Kraft, 2020). Correlations between financial education and healthy financial practices, even if small, succumb to the "chicken or the egg" problem: are the educated better at finance, or are those who are practicing good finance educating themselves more (Hastings et al., 2013)?

The thin availability and efficacy of formal financial education may lead young adults to seek different sources of information. Perhaps one of the most common of such

\footnotetext{
${ }^{1}$ Kraft (2020) proposed that effects that are less than $g=0.20$ can be considered "large" in educational intervention contexts. Specifically, Kraft suggested that "large" effects are at or above $g=0.20$, "medium" effects are between $g=0.05$ and $g=0.20$, and "small" effects are between $g=0$ and $g=0.05$. The overall median effect size of financial education intervention that Kaiser et al. (2020) meta -analysis was $g=0.098$. This effect size would be considered negligible by the "typical" standards (Cumming, 2012) and "medium" by Kraft's standards.
} 
alternative sources is parents. In fact, parents' financial socialization may present a stronger effect on financial practices of young adults than do school classes (e.g., LeBaron et al., 2019, 2020; Shim et al., 2009, 2010). For example, Shim et al. (2009) saw that among first-year college students, parental teaching yielded a much larger positive effect $(r=0.43)$ on healthy financial practices (e.g., keeping budgets) than did high school financial education $(r=0.13)$.

With the advent of the internet age, it has never been easier for people of any age to interact with the economy. Financial socialization may be occurring earlier in life. For example, the prevalence of online shopping has attracted young consumers, many of whom may have had no financial socialization in the past, to spend their money with a mere click of a button (e.g., Thaichon, 2017). With spending occurring earlier in life, young adults may benefit from saving socialization, especially in a domain with which many adults struggle: retirement preparation.

\section{Retirement Preparation}

For some time, scholars and practitioners have been sounding the alarm because Americans are not amassing enough funds through their career to gain financial independence and successfully retire (e.g., Benartzi \& Thaler, 2007, 2013; Morrissey, 2019; Thaler \& Benartzi, 2004). This is detrimental not only to adults' financial health, but it also has potential to trickle into their children's retirement preparation practices (or, lack thereof; Gudmunson \& Danes, 2011; Hancock et al., 2012).

There are many challenges in the path towards retirement preparation. Indeed, creating and sticking to a plan is no easy feat, even for a seemingly easy activity like grocery shopping (Gilbert et al., 2002). Retirement planning is difficult enough for adults who are nearing it (Petkoska \& Earl, 2009). Research has suggested that two particular hurdles can inhibit planning for retirement. Even if one may want to save, procrastination or inertia in saving can leave a retirement account sparse (Wiener \& Doescher, 2008). For young adults, planning for retirement decades in advance is an even bigger venture.

Recent qualitative research suggested that young adults have mixed feelings about retirement. Using a sample of members of the Millennial and Generation Z cohorts, Anderson and Gettings (2020) asked their participants to draw and to write about their idea of what is retirement and old age. They saw that their participants tended to have negative associations with aging (e.g., physical signs of aging) yet positive associations with retirement (e.g., leisure). Anderson and Gettings suggested that young adults' mixed feelings about retirement may indicate a shift in definition across generations: “...newer forms of retirement that boomers are constructing and enacting (e.g., where work still plays a central role) have yet to influence the anticipatory expectations of younger generational cohorts" (p. 13). Interestingly, old age itself can affect retirement preparation for young adults. Hershfield et al. (2011) found that young adults' retirement preparation attitudes increased after viewing a photo of themselves rendered to appear aged.

\section{The Current Research}

Young adults' picture of retirement may be positive, yet also appear blurry (Anderson \& Gettings, 2020). Young adults' motivation to learn about retirement may lead them to seek multiple sources for information. Yet, scholars and practitioners know very little about the newest generation's approach to retirement.

The purpose of this work was to explore whether young adults are actively discussing retirement with various sources in their social network and how such discussions are associated with retirement preparation (both attitudinal and behavioral). Additionally, this study serves to compare the relative effects of formal financial education (measured by the number of financial classes one has taken) and financial socialization. I identified two indices of financial socialization: the frequency of discussing retirement (i.e., how often one talks about the topic) and the diversity of retirement sources (i.e., with how many people one has discussed retirement). Using these two indices affords an examination of the relative contribution of both the quality (diversity of sources) and the quantity (general frequency of discussions) of financial socialization on retirement preparation.

The data analyzed in this research were collected as part of a larger study on the financial attitudes and behaviors of American members of Generation Z, which I defined to be persons born between 1995 and 2010. This study specifically included those aged 18 and over: the youngest eligible participants were thus born in 2002). ${ }^{2}$ Participants completed a set of questions pertaining to the following topics: retirement, debt, investing, financial technology use, home ownership, and financial knowledge. This study focuses on the questions about the topic of retirement.

\section{Hypotheses and Research Question}

Although this research is largely exploratory in nature, it is possible to propose several hypotheses based on prior literature (Shim et al., 2009, 2010):

\footnotetext{
2 To note, the definition of "Generation Z" fluctuates from source to source (Wiedmer 2015). The operationalization used in this research aims to be a compromise across definitions.
} 


\section{Hypothesis 1}

Using parents as a source of talking about retirement is positively associated with retirement preparation.

\section{Hypothesis 2}

Using co-workers as a source of talking about retirement is positively associated with retirement preparation.

\section{Research Question}

What associations with retirement preparation do various sources of conversation about retirement have?

\section{Method}

\section{Recruitment}

Participants were recruited from nationally-balanced panel suppliers via Alchemer (known as Survey Gizmo at the time of the study) throughout the month of April, 2020. Alchemer is an online survey hosting platform that partners with panel companies across the United States to collect data for researchers based on pre-determined sample criteria. I constrained the participants to be adult members of Generation Z - the age range was thus 18 (youngest possible participants) to 25 (oldest members of Generation $Z$ per the definition used in this study). Participants received \$3 USD for completing this survey in its entirety. The survey took approximately $10 \mathrm{~min}$ to complete.

\section{Participants}

A total of 1311 young adults partook in this study $\left(M_{\text {age }}=21.44, S D_{\text {age }}=2.34\right.$, Median $\left._{\text {age }}=21\right)$. The sample consisted of 468 men, 643 women, and 20 persons who reported to identify as another gender or who preferred not to disclose this information (these persons were excluded from any analysis of gender). ${ }^{3}$

\section{Procedure}

Persons volunteering to partake in this study began by entering their age. This question served as an eligibility check, as any persons who did not report to be between the ages of 18 and 25 were automatically disqualified from participating this study. Indices of retirement preparation included anticipated retirement age, importance of retirement knowledge,

\footnotetext{
3 Age and gender were the only demographic collected variables.
}

and emotions experienced when thinking about retirement. Questions on retirement preparation appeared first in the survey for all participants in this study.

\section{Measures}

See Appendix 1 for the full list of measures and their metrics. Participants answered a set of questions about retirement preparation, such as: perceived likelihood of retirement, anticipated retirement age, and perceived importance of learning about retirement. I assessed the sources of retirement conversations using the question "With whom have you discussed planning for retirement?" The nine sources were: parents, siblings, other family members, friends, significant others, co-workers, financial advisors, people on internet discussion forums, and "other sources." Participants had the option to select as many sources as they wished. Each source was coded $0=$ Have not spoken to source about retirement and $1=$ Have spoken to source about retirement. I computed the index of source diversity by counting the number of sources each participant selected-thus, the count can range from zero (discussed with no sources) to nine (discussed with all sources). The frequency of discussing retirement was measured using a single item, with higher scores reflecting greater frequency of discussing this topic.

\section{Data Preparation}

Although I did not drop any cases from the analyses, I marked a small set of responses on two questions as missing due to potential response inaccuracy. These questions were self-reported anticipated retirement age and the number of financial classes one has taken. The criteria were:

(1) Those who reported an anticipated retirement age younger age $45(n=50)$ or older than $93(n=4)$.

(2) Those who reported taking more than $12^{4}$ financial classes $(n=29)$.

\section{Behavioral Indices of Retirement Focus/Preparation}

Participants also engaged in two tasks that served as behavioral proxies of retirement preparation.

The first task was ranking 12 workplace benefits in order of importance. The benefits included in the list were: medical insurance, dental insurance, vision insurance, retirement benefits, life insurance, commuter benefits, paid vacation policy, health savings accounts, disability insurance, childcare assistance, paid parental leave, and flexible working

\footnotetext{
4 Among the 28 omitted cases, the range of classes one reported to have taken was $20-12,369,549,494$.
} 
Table 1 Descriptive statistics of the variables examined in this study

\begin{tabular}{|c|c|c|c|c|c|}
\hline Variable & Mean & SD & Median & Minimum & Maximum \\
\hline Frequency of talking about retirement & 2.12 & 1.73 & 2 & 0 & 6 \\
\hline Importance of learning about retirement & 3.76 & 1.88 & 4 & 0 & 6 \\
\hline Likelihood of retiring & 0.60 & 0.33 & 0.6 & 0 & 1 \\
\hline Anticipated retirement age & 65.02 & 7.34 & 65 & 45 & 93 \\
\hline Perceived retirement knowledge compared to peers & 2.78 & 1.67 & 3 & 0 & 6 \\
\hline Successful retirement compared to parents & 0.24 & 1.14 & 0 & -2 & 2 \\
\hline Successful retirement compared to grandparents & 0.17 & 1.29 & 0 & -2 & 2 \\
\hline Perceived retirement deposit rate of full-time workers & $6.04 \%$ & $3.13 \%$ & $5 \%$ & $0 \%$ & $11+\%$ \\
\hline Anticipated retirement contribution rate in full-time job & $6.17 \%$ & $3.22 \%$ & $5 \%$ & $0 \%$ & $11+\%$ \\
\hline Rank of workplace retirement benefits & 5.76 & 3.27 & 5 & 1 & 12 \\
\hline Money allocated for retirement & $\$ 169.50$ & $\$ 204.26$ & $\$ 100$ & $\$ 0$ & $\$ 1000$ \\
\hline Positive affect & 2.04 & 0.97 & 2 & 0 & 4 \\
\hline Negative affect & 1.78 & 0.98 & 1.75 & 0 & 4 \\
\hline Number of finance classes taken & 0.81 & 1.55 & 0 & 0 & 12 \\
\hline Total retirement conversation sources & 1.93 & 1.35 & 1 & 1 & 9 \\
\hline
\end{tabular}

The sample size for anticipated retirement age was smaller $(\mathrm{n}=977)$ because persons who reported a zero chance of retirement did not see this question

hours. This measure assumes that persons who are focusing on retirement preparation would find such workplace benefits to be more important than benefits distant from retirement as such benefits allow them to achieve their preparation goals. Negative correlations with this variable reflect greater preparation for retirement, as lower values are higher ranks (i.e., the lowest possible value [one] is the highest possible rank).

The second task was based on Hershfield et al. (2011) investigation of the effect of viewing photos of oneself rendered to appear aged on retirement savings. In this task, participants imagined receiving an unexpected \$1,000 and were given five options of how to use that money: buy something for themselves, buy something for another person, put the money into a retirement fund, put the money in a savings account, use it to pay off debt. The more one allots for retirement, the more retirement preparation they are exhibiting.

Table 1 contains the descriptive statistics for each variable analyzed in this study.

\section{Results}

\section{Analytic Overview}

Because of the large sample, effects negligible in size can yield seemingly "large" statistical significance. To avoid Type 1 error, I interpret a correlation as "significant" if it meets or exceeds the conventional criterion of a small effect before rounding ${ }^{5}$ ( $r=0.10$; Cohen, 1992). I applied the same criterion in regression analyses based on standardized slopes (i.e., $\beta \geq 0.10$ are "significant") and the omegasquared statistic in ANOVA tests (i.e., $\omega^{2}=0.01^{6}$ ). Similarly, I conclude that a between-groups effect is "significant" if it meets or exceeds the conventional criterion of a small effect (i.e., $d=0.20$; Cohen, 1992). Because $d$ can overestimate the size of the effect, however, I used Hedges's $g$ : a less biased derivative of $d$ (and is thus interpreted identically to it; Cumming, 2012). Due to multiple comparisons in the tests below, the criterion for statistical significance was $p<0.001$. Any effect of source reflects a difference between participants who have (vs. have not) spoken about retirement with each source (e.g., parents).

\section{Correlations Between Outcome Variables}

See Table 2 for correlations between the variables analyzed in this study. I began by analyzing age and gender. Only two correlations emerged, both with age. Specifically, age was associated negatively with perceived likelihood of retiring (i.e., older participants reported smaller likelihoods than did younger participants) and positively with frequency of talking about retirement (i.e., older participants reported talking about retirement more so than did younger participants).

\footnotetext{
5 Thus, correlations between .095 and .099 are not interpreted as statistically significant despite being rounded up to .10 .

${ }^{6}$ The $\omega^{2}$ is interpreted similarly to the $R^{2}$ statistic. A $\omega^{2}$ of .01 corresponds to $r=.10$.
} 


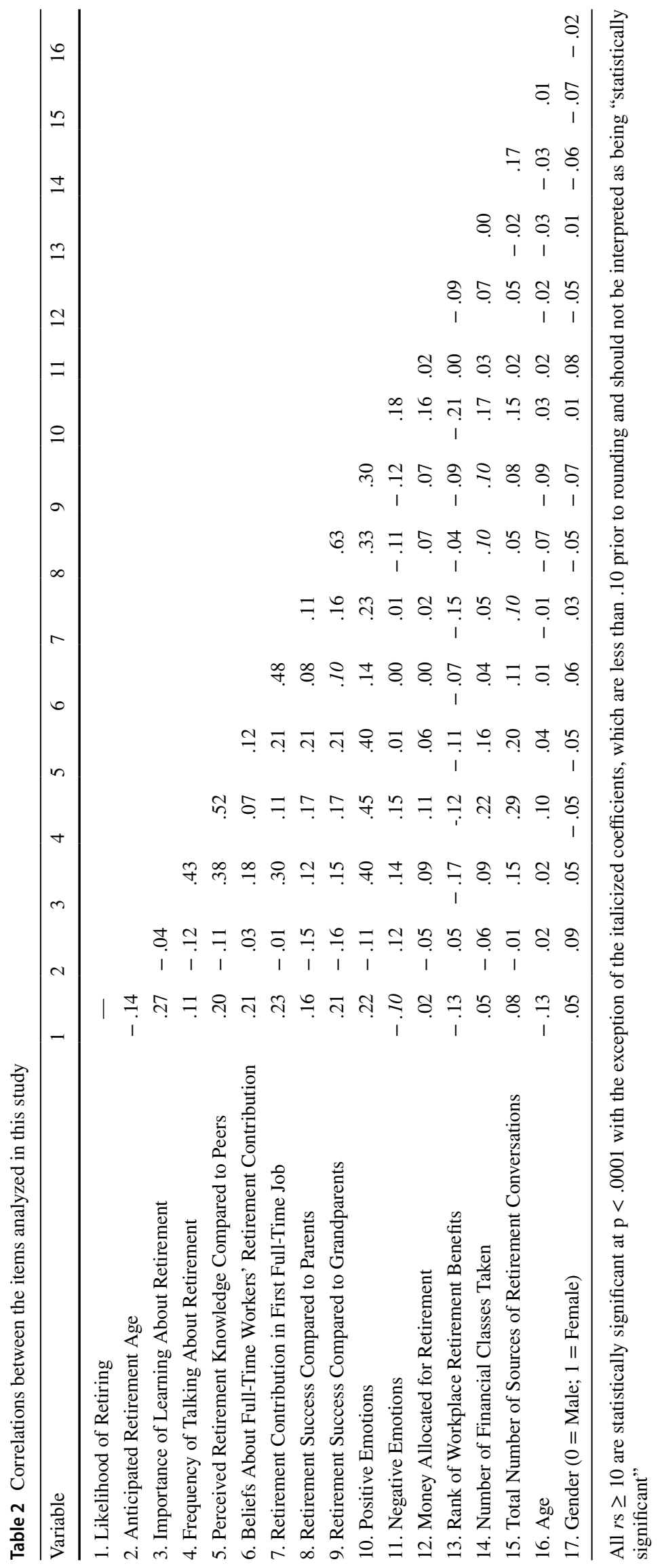


Fig. 1 Statistically-significant differences between employment status groups. Error bars represent standard error of the mean, displayed at the bottom of each bar

\section{YOUNG ADULTS' RETIREMENT CONVERSATION}

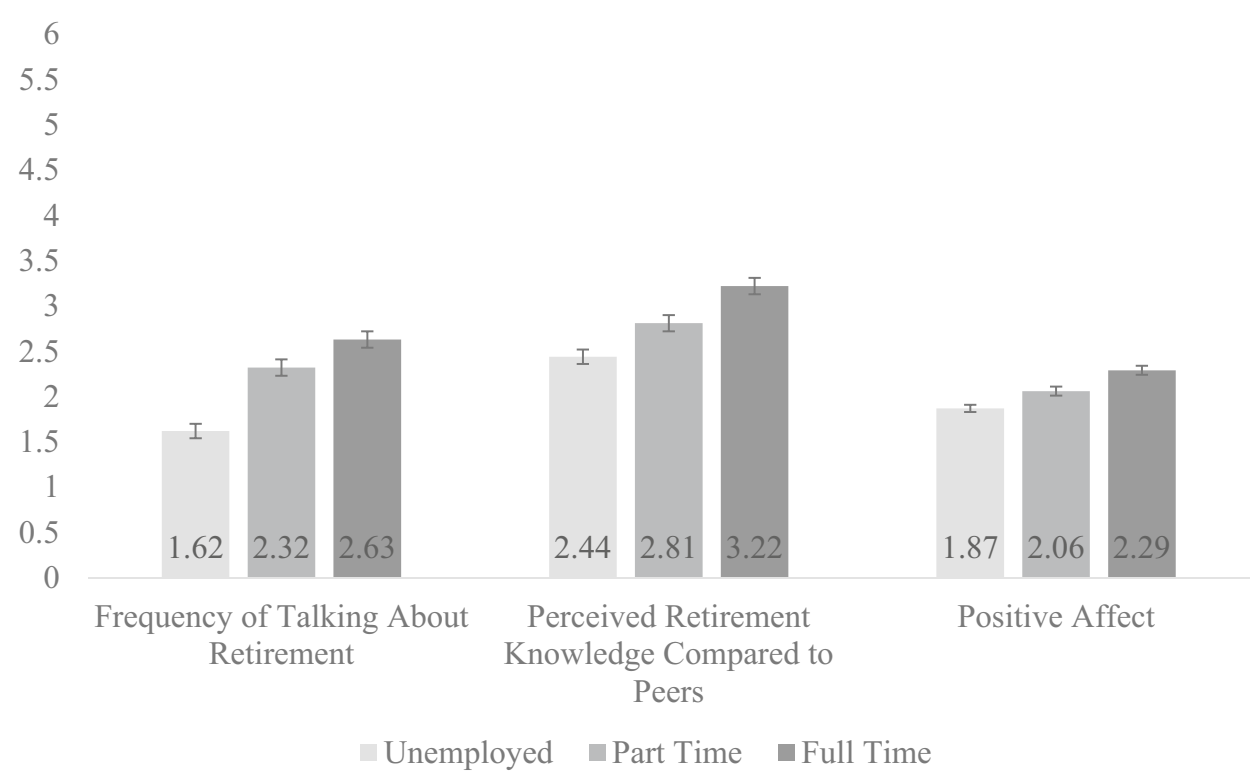

The frequency of talking about retirement yielded sizeable correlations with perceived importance of learning about retirement, perceived retirement knowledge compared to peers, anticipated retirement contribution in a full-time job, and positive emotions about retirement. The only variable with which the frequency of talking about retirement was unassociated was money allocated towards retirement in the allocation task. In other words, talking about retirement was generally positively associated with retirement preparation.

\section{Does Employment Status Predict Retirement Preparation?}

I conducted a set of one-way ANOVAs on the indices of retirement preparation in which the independent variable was employment status (unemployed vs. employed part time vs. employed full time). Employment status yielded three effects (see Fig. 1).

The first effect was for the frequency of talking about retirement, $F(2,1128)=37.45, \omega^{2}=0.06, p<0.0001$. Participants who were unemployed reported talking less about retirement compared to participants who were employed part time $(g=0.43)$ or full time ( $g=0.60$; both $p s<0.0001)$, who did not largely differ from one another $(g=0.18, p=0.0419)$.

The second effect was for perceived knowledge of retirement compared to peers, $F(2,1128)=21.08, \omega^{2}=0.03$, $p<0.0001$. Post-hoc tests revealed one difference: participants employed full-time reported perceiving greater knowledge of retirement relative to their peers compared to unemployed participants $(g=0.46, p<0.0001)$. Participants employed part time did not reach statistical significance in their differences with unemployed participants
( $g=0.23, p=0.0042)$ and those working full-time $(g=0.25$, $p=0.0043)$.

Lastly, employment status was associated with positive affect when thinking about retirement, $F(2,1128)=18.02$, $\omega^{2}=0.03, p<0.0001$. Post hoc tests showed one difference: participants employed full time showed greater positive affect than did participants who were unemployed $(g=0.42$, $p<0.0001)$. Participants employed part time did not demonstrate statistically-significant differences with participants who are unemployed $(g=0.20, p=0.0149)$ or employed full time $(g=0.25, p=0.0057)$.

\section{With Which Sources Have Participants Spoken About Retirement?}

Parents were the most common source of our sample's retirement discussions $(50.66 \%)$. This was followed by friends (31.56\%), significant others $(28.74 \%)$, siblings $(21.75 \%)$, "other sources" (18.04\%), other family members (16.53\%), co-workers (11.14\%), financial advisors (10.08\%), and internet forums $(4.60 \%)$. Because relatively few people in the sample talked about retirement with other family members, co-workers, financial advisors, internet forums, and other sources, any results of tests examining these sources should be interpreted with caution.

Age was positively correlated with speaking with a significant other about retirement $(r=0.12, p<0.0001)$. Gender was related only to discussing retirement with a significant other: women $(33.14 \%)$ were somewhat more likely to talk to a significant other than were men $(23.29 \%), \chi^{2}(1)=12.73$, $V=0.11, p=0.0004$. 
Journal of Family and Economic Issues (2022) 43:621-636

627

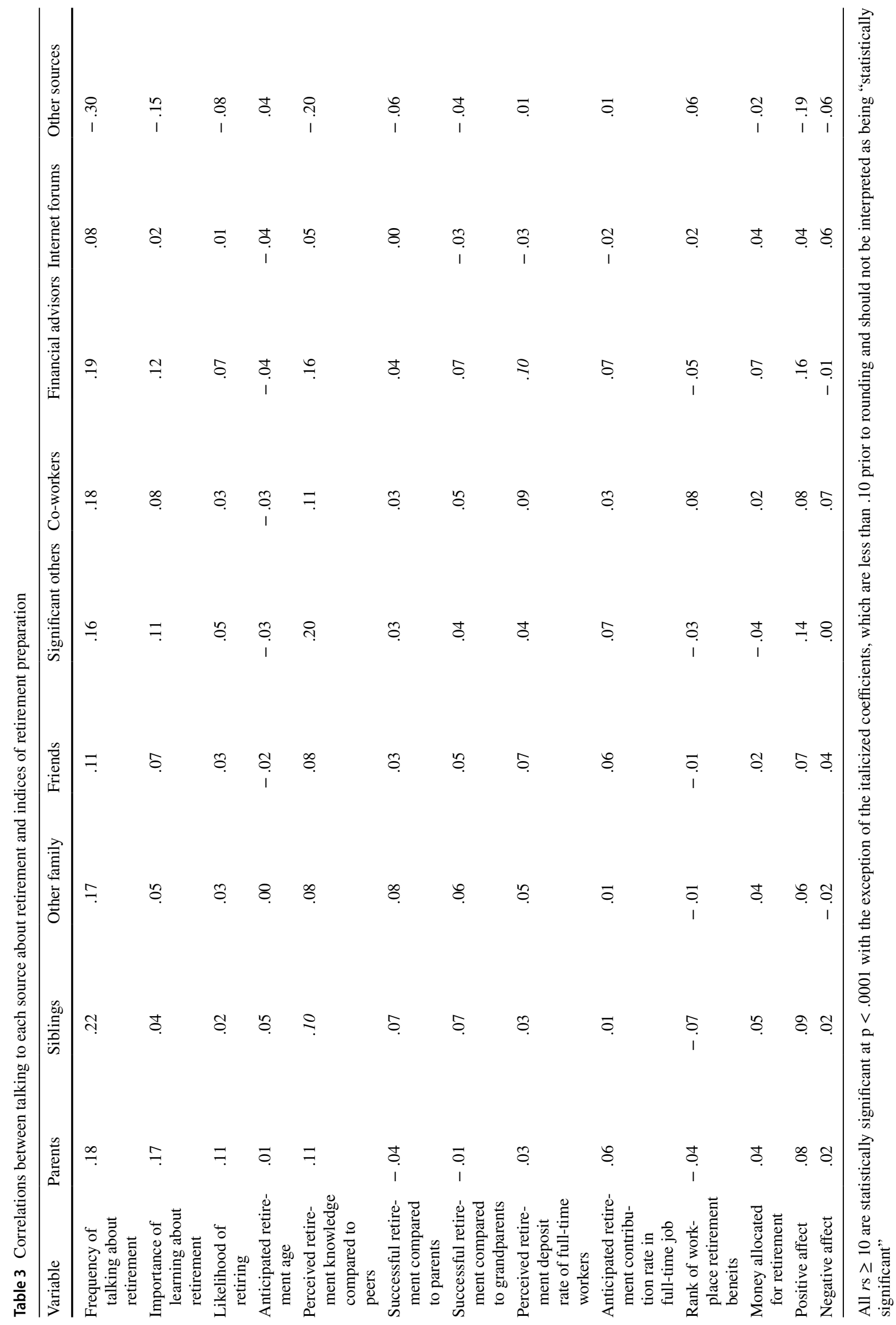

Springer 
Table 4 Effects of talking to particular sources on retirement preparation

\begin{tabular}{|c|c|c|c|c|}
\hline Source & Dependent variable & Spoken to source & Not spoken to source & $g$ \\
\hline \multirow[t]{4}{*}{ Parents } & Frequency of talking about retirement & $2.43(1.68)$ & $1.81(1.73)$ & 0.36 \\
\hline & Importance of learning about retirement & $4.07(1.73)$ & $3.43(1.98)$ & 0.34 \\
\hline & Likelihood of retiring & $63.60 \%(32.65 \%)$ & $56.67 \%(32.92 \%)$ & -0.21 \\
\hline & Perceived retirement knowledge compared to peers & $2.95(1.57)$ & $2.60(1.75)$ & -0.21 \\
\hline \multirow[t]{4}{*}{ Significant other } & Frequency of talking about retirement & $2.56(1.76)$ & $1.95(1.69)$ & 0.35 \\
\hline & Importance of learning about retirement & $4.08(1.77)$ & $3.63(1.91)$ & 0.25 \\
\hline & Perceived retirement knowledge compared to peers & $3.30(1.57)$ & $2.57(1.66)$ & 0.45 \\
\hline & Positive affect & $2.26(0.98)$ & $1.96(0.95)$ & 0.32 \\
\hline \multirow[t]{4}{*}{ Financial advisor } & Frequency of talking about retirement & $3.09(1.75)$ & $2.02(1.70)$ & 0.62 \\
\hline & Importance of learning about retirement & $4.43(1.70)$ & $3.68(1.88)$ & 0.42 \\
\hline & Perceived retirement knowledge compared to peers & $3.60(1.60)$ & $2.68(1.65)$ & 0.56 \\
\hline & Positive affect & $2.50(0.92)$ & $1.99(0.06)$ & 0.53 \\
\hline Siblings & Frequency of talking about retirement & $2.85(1.75)$ & $1.92(1.67)$ & 0.54 \\
\hline Other family members & Frequency of talking about retirement & $2.79(1.72)$ & $1.99(1.70)$ & 0.46 \\
\hline Friends & Frequency of talking about retirement & $1.99(1.77)$ & $2.42(1.61)$ & 0.25 \\
\hline \multirow[t]{2}{*}{ Co-workers } & Frequency of talking about retirement & $3.02(1.59)$ & $2.01(1.72)$ & 0.62 \\
\hline & Perceived retirement knowledge compared to peers & $3.32(1.54)$ & $2.71(1.67)$ & 0.38 \\
\hline \multirow[t]{4}{*}{ "Other sources" } & Frequency of talking about retirement & $1.02(1.41)$ & $2.37(1.70)$ & 0.86 \\
\hline & Importance of learning about retirement & $3.14(2.03)$ & $3.89(1.82)$ & 0.39 \\
\hline & Perceived retirement knowledge compared to peers & $2.07(1.75)$ & $2.93(1.61)$ & 0.51 \\
\hline & Positive affect & $1.66(0.95)$ & $2.13(0.95)$ & 0.50 \\
\hline
\end{tabular}

\section{Preparing for Retirement: Whom to Talk To?}

Table 3 contains correlation coefficients between talking to each source about retirement and the indices of retirement preparation. The sources that yielded the largest number of positive correlations were parents (partially supporting Hypothesis 1), significant others, and financial advisors. Seeking conversation about retirement in internet forums was unrelated to any variables analyzed in this study. Interestingly, the data suggested that speaking with "other sources" was negatively related to retirement preparation.

I extended these correlational analyses by estimating effect sizes for between-group differences (talked to vs. not talked to each source) in the variables that yielded correlations at or above $r=0.10$ (see Table 4). Across all sources besides "other sources," sizable differences in the frequency of talking about retirement emerged, with the biggest differences emerging for the sources of a financial advisor and co-workers. Talking to parents, significant others, financial advisors, and co-workers was associated with greater retirement knowledge compared to peers (demonstrating some support for Hypotheses 1 and 2). Only talking to parents was associated with retirement likelihood: those who have discussed retirement with their parents believed that they had a higher chance of successfully retiring than those who did not discuss retirement with their parents. Talking about retirement with significant others and with financial advisors was associated with positive emotions about retirement. Talking to "other sources," however, yielded opposite effects: talking to these sources was associated with decreased frequency of talking about retirement, importance of learning about retirement, less retirement knowledge relative to peers, and less positive affect about retirement.

\section{Multiple Regression Analyses of Conversation Sources}

To delve deeper into the effect of source on retirement preparation, I ran a set of multiple regressions. In these tests, I included all sources of conversation about retirement as well as the number of financial classes one has taken. These tests also had two covariates: the frequency of talking about retirement (with the exception of the regression in which this was the dependent variable) and the number of financial classes one has taken. This allowed me to examine any relative contribution of talking about retirement and formal education on retirement preparation. Because the frequency of talking about retirement was correlated with both age and employment status, I included them as covariates in this regression test. For the same reason, the analysis of perceived retirement knowledge compared to peers included employment status as a covariate. Statistically significant effects of source emerged for four variables (see Table 5). 
Table 5 Multiple regression analyses of the unique contributions of sources on retirement preparation

\begin{tabular}{|c|c|c|c|c|c|}
\hline Outcome & Predictor & $b$ & $S E$ & $\beta$ & $p$ \\
\hline \multirow{13}{*}{$\begin{array}{l}\text { Frequency of talking about } \\
\text { retirement }\end{array}$} & Parents & 0.14 & 0.11 & 0.04 & .1989 \\
\hline & Siblings & 0.56 & 0.12 & 0.13 & $<.0001$ \\
\hline & Other family & 0.20 & 0.14 & 0.04 & .14 \\
\hline & Friends & -0.05 & 0.11 & -0.01 & .6243 \\
\hline & Significant others & 0.23 & 0.11 & 0.06 & .0363 \\
\hline & Financial advisors & 0.42 & 0.17 & 0.07 & .0113 \\
\hline & Internet forums & 0.39 & 0.23 & 0.05 & .0871 \\
\hline & Co-workers & 0.45 & 0.16 & 0.08 & .0066 \\
\hline & "Other sources" & -0.88 & 0.14 & -0.20 & $<.0001$ \\
\hline & Number of financial classes taken & 0.14 & 0.03 & 0.13 & $<.0001$ \\
\hline & Age & 0.04 & 0.02 & 0.06 & .0462 \\
\hline & Employment (unemployed vs. part time) & 0.49 & 0.11 & 0.13 & $<.0001$ \\
\hline & Employment (unemployed vs. full time) & 0.66 & 0.12 & 0.17 & $<.0001$ \\
\hline \multirow{11}{*}{$\begin{array}{l}\text { Importance of learning } \\
\text { about retirement }\end{array}$} & Parents & 0.48 & 0.11 & 0.13 & $<.0001$ \\
\hline & Siblings & -0.43 & 0.13 & -0.09 & .0012 \\
\hline & Other family & -0.16 & 0.15 & -0.03 & .2819 \\
\hline & Friends & 0.16 & 0.12 & 0.04 & .1834 \\
\hline & Significant others & 0.23 & 0.12 & 0.06 & .047 \\
\hline & Financial advisors & 0.23 & 0.18 & 0.04 & .1915 \\
\hline & Internet forums & -0.09 & 0.25 & -0.01 & .717 \\
\hline & Co-workers & -0.16 & 0.18 & -0.03 & .3692 \\
\hline & "Other sources" & 0.08 & 0.15 & 0.02 & .5834 \\
\hline & Number of financial classes taken & -0.04 & 0.03 & -0.03 & .2441 \\
\hline & Frequency of talking about retirement & 0.47 & 0.03 & 0.44 & $<.0001$ \\
\hline Outcome & Predictor & $b$ & $S E$ & $\beta$ & $p$ \\
\hline \multirow{13}{*}{$\begin{array}{l}\text { Perceived retirement } \\
\text { knowledge compared to } \\
\text { peers }\end{array}$} & Parents & 0.10 & 0.10 & 0.03 & .278 \\
\hline & Siblings & -0.15 & 0.11 & -0.04 & .184 \\
\hline & Other family & -0.08 & 0.12 & -0.02 & .527 \\
\hline & Friends & 0.08 & 0.10 & 0.02 & .413 \\
\hline & Significant others & 0.42 & 0.10 & 0.12 & $<.0001$ \\
\hline & Financial advisors & 0.24 & 0.15 & 0.04 & .111 \\
\hline & Internet forums & -0.02 & 0.21 & -0.002 & .933 \\
\hline & Co-workers & -0.05 & 0.15 & -0.01 & .746 \\
\hline & "Other Sources" & -0.03 & 0.13 & -0.01 & .831 \\
\hline & Number of financial classes taken & 0.03 & 0.03 & 0.03 & .242 \\
\hline & Frequency of talking about Retirement & 0.47 & 0.03 & 0.49 & $<.0001$ \\
\hline & Employment (unemployed; part time) & -0.01 & 0.10 & -0.002 & .942 \\
\hline & Employment (unemployed vs. full time) & 0.17 & 0.11 & 0.04 & .126 \\
\hline \multirow{11}{*}{$\begin{array}{l}\text { Ranking of workplace } \\
\text { retirement benefits }\end{array}$} & Parents & -0.11 & 0.22 & -0.02 & .6225 \\
\hline & Siblings & -0.33 & 0.26 & -0.04 & .2075 \\
\hline & Other family & 0.12 & 0.28 & 0.01 & .6757 \\
\hline & Friends & -0.18 & 0.23 & -0.03 & .4229 \\
\hline & Significant others & -0.01 & 0.23 & -0.002 & .9522 \\
\hline & Financial advisors & -0.46 & 0.34 & -0.04 & .1778 \\
\hline & Internet forums & 0.33 & 0.48 & 0.02 & .4856 \\
\hline & Co-workers & 1.15 & 0.34 & 0.11 & .0008 \\
\hline & "Other sources" & 0.17 & 0.30 & 0.02 & .5646 \\
\hline & Number of financial classes taken & 0.05 & 0.07 & 0.02 & .4684 \\
\hline & Frequency of talking about retirement & -0.20 & 0.06 & -0.11 & .0012 \\
\hline
\end{tabular}




\section{Frequency of Talking About Retirement}

Siblings and financial classes were sources of talking about retirement when controlling for all other variables. Talking to "other sources," however, was negatively related to the frequency of retirement conversations.

\section{Importance of Learning About Retirement}

Talking to parents was the only positive correlate of perceived importance of learning about retirement, when controlling for talking about retirement with the rest of the sources. The frequency of talking about retirement also served as a positive predictor, suggesting that talking about the topic in general promotes its importance.

\section{Perceived Retirement Knowledge Compared to Peers}

Participants who had discussed retirement with their significant other were more likely to believe that their knowledge of retirement was greater than that of their peers. The frequency of talking about retirement was also a positive predictor of this variable.

\section{Ranking of Retirement Benefits}

Discussing retirement with co-workers was related to higher rankings of workplace retirement benefits. In other words, the more that participants spoke about retirement to their co-workers, the more important they felt are employer retirement benefits. Rankings of workplace retirement benefits were also positively correlated with the frequency of talking about retirement.

\section{Quantity vs. Frequency of Retirement Conversations}

In another set of analyses, I regressed the indices of retirement preparation on the frequency of talking about retirement, the diversity of sources one has to talk about it, and the number of financial classes one has taken. The purpose of these tests was to parse the relative influence of formal financial education from "informal" discussion within one's social network; and whether the diversity of conversation sources differs from the frequency of discussing retirement in shaping retirement preparation.
Several relations emerged, all for the frequency of talking about retirement. Specifically, the frequency of talking about retirement positively predicted: anticipated retirement age $(\beta=0.12)$; importance of learning about retirement $(\beta=0.44)$; knowledge of retirement compared to peers $(\beta=0.51){ }^{7}$ retirement success compared to parents ( $\beta=0.16)$ and grandparents $(\beta=0.15)$; ranking of workplace retirement benefits $(\beta=-0.11)$; and both positive $(\beta=0.43)$ and negative $(\beta=0.16)$ emotions about retirement; all $p$ s $<0.0001$. No effects emerged for financial classes taken and the number of sources with whom one has discussed retirement.

\section{Discussion}

Nearly half of Americans may not be adequately prepared for retirement (Munnell et al., 2018). This is a problem not just for persons nearing or entering retirement, but for young adults who are just beginning to build their financial life. As past research shows, young adults do find retirement and finance to be interesting and show motivation to learn more about it (Beck \& Garris, 2019). In this study, I explored whether young adults go to various sources for information on retirement, and whether these sources differentially related to retirement planning.

The results of this research echo young adults' interest in finance (Beck \& Garris, 2019). They generally acknowledged the importance of knowledge about retirement and even felt that they may know more than their peers do about the subject. The sample also had a fairly positive outlook on retirement. Participants experienced more positive than negative emotions; and believed that they will be at least as successful at retirement, if not more, compared to their parents and grandparents. Exploratory tests also showed that employed young adults (especially those employed full time) tended to display somewhat more retirement preparation compared their unemployed counterparts. This may not be surprising as retirement preparation often begins at the workplace with a retirement benefits plan.

\section{Sources of Retirement Conversations}

Just like a portfolio, diversification in sources of conversation about retirement yields benefits. Participants with more sources of retirement tended to display more retirement preparation. A greater number of retirement conversation sources was positively associated with variables such as importance of learning about retirement, knowledge of

\footnotetext{
${ }^{7}$ Including employment status as a covariate in this regression yielded no main effects $(\beta \mathrm{s}<0.05)$ and did not change the overall results (the $\beta$ for frequency of talking about retirement was 0.50 in this regression).
} 
retirement relative to peers, and positive emotions about retirement. This finding suggests that different sources may offer unique insights into retirement preparation, suggesting that young adults can benefit from talking about retirement with numerous others in unique ways. Indeed, examinations of each source separately revealed support for this notion.

Parents were the most common source of retirement conversations in the sample. Participants who talked to parents generally felt that retirement is more important to learn about, anticipated a higher likelihood of retiring, and believed that they knew somewhat more about retirement relative to their peers. Out of all the potential sources, parents are likely the one with whom young adults interact the most. In fact, during the time of this study (April, 2020), approximately $51 \%$ of Americans ages 18-29 were living with at least one parent (Fry et al., 2020). ${ }^{8}$ Young adults curious about retirement may be proactively seeking advice from their parents-seeking information from this source is especially simple if they are cohabitating. On the other hand, parents themselves vary in their desire to talk about retirement with their children (e.g., LeBaron et al., 2019). Perhaps the parents who are preparing for retirement themselves proactively seek to discuss the retirement process with their children.

Still, parents were not the only predictor of the frequency of talking about retirement. Participants also discussed retirement with their close social network; particularly friends and significant others. Conversations with close others can span a library's worth of topics. Yet, it appears that young adults are choosing to discuss retirement specifically. In other words, young adults want to actively discuss retirement and appear to do so with multiple sources.

The null relation between internet forums and the frequency of talking about retirement is interesting. Generation $\mathrm{Z}$ is tech-centered, growing up after the internet became a household staple. These findings suggest that although the internet is ripe with knowledge waiting to be discovered, it may not currently be a significant source of retirement information for young adults. Rather, it appears that young adults prefer discussing retirement with people whom they know. Why discussing retirement via internet forums is unrelated to retirement preparation is an empirical question. Although a speculation, young adults may prefer using the internet for other ventures (e.g., shopping, streaming services), especially during the COVID-19 pandemic, rather than seeking financial information (Vogels, 2020).

Unlike the rest of the sources analyzed in this research, talking to "other sources" about retirement yielded negative relations with retirement preparation. It is challenging

\footnotetext{
${ }_{8}$ I did not assess housing status-I had no data on whether the participants lived with a parent at the time of the study.
}

to surmise why such negative correlations emerged for this source given that source diversity has generally yielded a positive effect in this research. Indeed, the conceptualization of "other" can differ person to person. Future research should identify which of such sources of information could yield detrimental effects.

Two sets of multiple regression analyses expanded this story. The first set of tests served to examine whether any particular source of retirement conversations predicts retirement preparation above and beyond other sources, potentially identifying the most effective source. Findings from these tests suggested that no source stood out as an especially-strong predictor. Rather, the effect of source of retirement conversations varied across both the source itself and the index of retirement preparation. Parents served as one of the most impactful sources. For example, parents were the sole predictor of the perceived importance of retirement. Just like with any other financial topic, financial socialization for retirement may begin at home. Indeed, parents tend to be the first financial educators to children, and the lessons they teach appear to transcend into adulthood (Webley \& Nyhus, 2006). Perhaps parents who speak to their children about retirement provide a "head start," thereby showing the importance of proper retirement preparation earlier in life.

Only siblings and financial classes remained predictors of the frequency of talking about retirement. Indeed, retirement appears in financial curricula (e.g., Washington State Department of Financial Institutions, 2020), thereby inherently increasing the frequency of discussions about it. Why discussing retirement with siblings predicted the frequency of talking about retirement is more difficult to explain. A potential explanation is that people tend to seek practical advice more so than emotional support from their siblings (Voorpostel \& van der Lippe, 2007). Further research is needed to examine these associations in more detail.

Third, the source that appeared to boost one's perceived knowledge of retirement relative to their peers was discussing it with one's significant other. One hallmark of close relationships is need support, which includes supporting the need for competence (La Guardia and Patrick, 2008). Perhaps close relationships can extend towards boosting confidence in one's financial skills (whether the increased confidence will beget competence, however, is an empirical question).

The final set of effects was on positive emotions about retirement, which only speaking to financial advisors and taking financial classes predicted positively. Financial advisors and financial classes share some overlap, as both serve to provide objective financial information and provide some decision-making guidance. Perhaps kindled by young adults' desire to learn about finance, this guidance can evoke even more positive emotions with retirement than they may already experience (Beck \& Garris, 2019). 
A second set of tests examined relative contributions of the frequency of talking about retirement, the number of sources one has to talk about retirement, and the number of financial classes one has taken on retirement preparation. Across all variables, only the frequency of talking about retirement predicted retirement preparation. This finding highlights the importance of continuous conversation about the topic. Perhaps those who engage in constant conversation on the topic, even if it is only with a few sources, receive positive validation and reinforcement on retirement planning, especially if their close social network is supportive of their goals (Rusbult et al., 2009). Interestingly, frequency of talking about retirement was correlated positively to both positive and negative emotions about retirement. This finding reflects prior research showing young adults' mixed feelings towards retirement (Anderson \& Gettings, 2020). Young adults may see the concept of achieving retirement through a positive lens while seeing the concept of reaching retirement negatively given its association with aging.

\section{Behavioral Measures}

The two behavioral measures used in this study (ranking of workplace benefits and money allocated to retirement in the allocation task) yielded correlations with several indices of retirement preparation. First, people who rank workplace retirement benefits higher also tend to anticipate higher chances of retiring, acknowledge the importance of learning about retirement, talk about retirement often, perceive knowing about retirement more than their peers do, anticipate contributing more to their retirement fund in a hypothetical first job, and experience positive emotions when thinking about retirement. Second, the amount of money one allocated towards retirement was related to two variables: the frequency of talking about retirement positive emotions when thinking about retirement. These correlations further demonstrate the importance of simply discussing retirement on retirement preparation, both attitudinal and behavioral.

Interestingly, no retirement conversation source was associated with the two behavioral measures. In other words, although talking about retirement to certain sources (e.g., parents) may bolster young adults' retirement preparation attitudes, their behavioral preparation is still at the starting line. This attitude-behavior discrepancy may reflect the intentionaction gap: a disconnect between planning (which appears to be relatively high in this sample) and acting (Sheeran \& Webb, 2016), which is seen fairly often in retirement preparation (Krijnen et al., 2018). People may plan on saving for retirement, yet they do not actually do so. This is perhaps why auto-enrollment retirement plans (i.e., plans that automatically enroll employees into a retirement fund) have shown to be successful in increasing savings (Benartzi \& Thaler, 2007): the action is already done for them independent of intention.
Alternatively, perhaps young adults, despite showing interest in learning about it, have little experience in the behavioral processes of retirement preparation. It is possible that as they enter the workforce and begin retirement planning, their behaviors may change as well. In other words, the principles of cognitive dissonance theory (Harmon-Jones \& Harmon-Jones, 2007) may be at play. Cognitive dissonance is the unpleasant experience due to a "misalignment" between one's attitudes and behaviors. To alleviate this discomfort, people can change either their attitude or their behavior. Per this idea, developing positive attitudes about retirement without implementing parallel action could lead to dissonance that one can alleviate by engaging in preparatory behaviors, perhaps even beginning to save.

\section{Financial Classes}

Prior work has shown that formal financial education, such as high school classes, may not be preparing young adults for financial health as much as many may think (e.g., Shim et al., 2010). I was able to explore whether the number of financial classes one has taken (which serves as a proxy for financial education) can capture unique variance in retirement preparation independent of other sources. The results showed that formal education was largely unrelated to any index of retirement preparation, further suggesting that the home could prepare one better than can the classroom. In fact, the frequency of talking about retirement was the only variable to predict both behavioral indices of retirement preparation (along with positive emotions towards retirement). The implication of this finding is that retirement preparation begins with talking. It appears that the conversations that young adults have about retirement are largely constrained to their close social network, especially with parents.

These results also echo the advantages of seeking help from financial advisors. In fact, the financial advisor was the only source outside of one's social network to play a positive role in retirement preparation. Thus, young adults could benefit from using financial advisors to start their financial journey.

\section{Strengths and Limitations}

\section{Strengths}

There are a number of strengths of this research. First, this was the first study (to my knowledge) to explore the sources of conversations that young adults have available to discuss retirement. Second, the sample provided ample power to detect effects. Due to this, I was conservative in interpreting effects as "significant" with the goal of reducing Type I errors. Third, the sample was drawn to be 
nationally-balanced and may be a more precise reflection of young adults' attitudes and behaviors compared to a convenience college student or online sample.

\section{Limitations}

This study has several important limitations to both its sample and its design.

Limitations to the Sampling Strategy Despite being balanced, the sample may still not precisely reflect the attitudes and behaviors of young adults given the significant diversity of their generation (Pew, 2018). Still, the difference in "representativeness" between balanced and "true" random samples (e.g., random digit dialing) is generally small (Goel et al., 2015). Another limitation to this sample was the age restriction. Many members of Generation $\mathrm{Z}$ are younger than 18 and yet are participating in the economythe results of this work may thus not accurately reflect the financial attitudes and practices of the younger members of this generation. The financial incentive to participate in the survey (\$3) may have also contributed to selection bias. Past research has linked monetary compensation with data and showed that said compensation is a common motivation for partaking in paid online surveys (e.g., Litman et al., 2015). Given that this study focused on finances, there may have been underlying financial motivation for participants to complete this study. It is thus possible that this research missed responses from a particular demographic: financially well-off young adults. Indeed, those who are financially well off may be less apt to partake in research either because they are less likely to participate in paid research in general or because the financial incentive to participate was insufficient for them.

Limitations to the Design First, the results of this study are correlational in nature and should not be interpreted causally. Future experimental work could encourage young adults to talk about retirement with parents (or to other sources) to explore causal links. Second, participants were able to select only nine potential sources of conservation about retirement, which omits a potentially larger pool of sources. As the results of this research show, "other" sources demonstrate negative effects on preparation, suggesting that sources not identified in this research have different effects compared to sources that were assessed. Thus, future research should identify further sources of conversation about retirement to better understand their relation.

Limitations Due to the Climate During Data Collection The data collection unintentionally occurred during the SARSCoV-2 pandemic over two weeks in April of 2020 (this work was planned prior to the outbreak). This is likely the first major world event for members Generation Z. ${ }^{9}$ Data collection during this time, however, allows researchers to examine whether this unique historical event influenced young adults' experiences in their entry into the finance and the working world. Of course, the results may not accurately represent young adults' financial attitudes and behaviors during times of normalcy. Additionally, the negative economic impact of the pandemic may have provided unique incentives for young adults to participate in paid online research as means of income supplementation.

\section{Future Directions}

A number of doors are waiting to be opened in future research. First, researchers would benefit from exploring whether sources of conversations about retirement, as well as attitudes and behaviors towards it, changes as the world recovers from COVID-19. Such work would provide insights into how global economic downturns impact young adults' financial habits. Researchers would also benefit from examining whether the effect of discussing retirement with various sources differs across age groups. For example, perhaps older adults would benefit less in talking to their parents than would younger adults. Another interesting direction is a longitudinal investigation to examine whether any boosts in retirement preparation from discussing the topic with various sources are short- or long-term.

\section{Conclusion}

Planning for retirement is difficult for a number of reasons. Older adults may be realizing that they have not adequately prepared for retiring (Morrissey, 2019), whereas younger adults may not even think about retirement altogether (Hershfield et al., 2011). Of course, the earlier one starts financial socialization the better; and this financial socialization begins and continues with parents. After all, as the results of this research and those of prior studies suggest, finance classes can boost confidence, but talking about finance with parents can boost competence- - though talking to siblings, friends, significant others, and especially a professional, is also beneficial.

\footnotetext{
${ }^{9}$ With the exception of some of the oldest members of this generation, who have lived through and may even remember the events of 9/11/2001.
} 


\section{Appendix 1}

\section{Measures Used in this Study}

\section{Indices of Retirement Preparation}

\section{Likelihood of Retirement}

"Using your best guess, what's the likelihood that you'll retire in the future?" The scale for this item was: $0 \%, 10 \%$, $20 \%, 30 \%, 40 \%, 50 \%, 60 \%, 70 \%, 80 \%, 90 \%, 100 \%$.

\section{Anticipated Retirement Age}

"At what age do you think you'll retire?" This item was open-ended.

\section{Importance of Learning About Retirement}

"How important is learning about retirement planning to you?" The scale for this item was: $0=$ Unimportant; $6=$ Very important.

\section{Frequency of Talking About Retirement}

"How often do you talk about retirement with others?" Scale: $0=$ Never; $6=$ Very often.

\section{Perceived Knowledge of Retirement Compared to Peers}

"How would you compare your knowledge of retirement preparation to other people your age?" The scale for this item was: $0=\mathrm{I}$ know much less than others do; $6=\mathrm{I}$ know much more than others do.

\section{Beliefs About Full Time Workers' Retirement Deposit Rate}

"What percent of each paycheck do you think full-time workers save for retirement?" The scale for this item was: $0 \%, 1 \%, 2 \%, 3 \%, 4 \%, 5 \%, 6 \%, 7 \%, 8 \%, 9 \%, 10 \%, 11+\%$.

\section{Anticipated Retirement Savings Rate at First Full-Time Job}

"Imagine you just started your first job. As a part of the on boarding process, your new company asks what percent of your paycheck you'd like to deposit into a retirement savings account. What percent would you choose?" The scale for this item was: $0 \%, 1 \%, 2 \%, 3 \%, 4 \%, 5 \%, 6 \%, 7 \%, 8 \%, 9 \%$, $10 \%, 11+\%$.
Perceived Retirement Success Compared to Parents and Grandparents

'Compared to your parents' [grandparents'] generation, how successful do you think you'll be at maintaining a comfortable life during retirement?" The scale for these items was: $-2=$ Much less successful; $-1=$ A little less successful; $0=$ About as successful; 1 =A little more successful; $2=$ Much more successful.

\section{Emotions About Retirement}

Positive emotions were: enthusiastic, determined, excited, and interested (composite index of positive affect was an average of these four items; $a=0.83$ ). Negative emotions were: distressed, uncertain, scared, and nervous (composite index of negative affect was an average of these four items; $a=0.81$ ). The scale for these items was: $0=$ Not at all; $1=$ A little; 2=Moderately; $3=$ Quite a bit; $4=$ Very much.

\section{Other Measures}

\section{Financial Classes Taken}

"How many financial planning classes have you taken in school so far? If you've never taken a class on this or on a similar topic, please enter a zero." This item was open-ended.

\section{Employment Status}

"Are you currently employed?" The responses were coded: $0=$ Unemployed; $1=$ Employed part time; $2=$ Employed full time.

Acknowledgements I would like to thank Steve Wendel for insightful comments on an earlier version of this manuscript.

Funding This project was fully-funded by Morningstar, Inc.

Data Availability The data, the materials, and the R code are available at https://doi.org/10.17605/OSF.IO/EB6SJ.

I declare no conflict of interest.

\section{Declarations}

Research Involving Human Participants This study followed the guidelines of human subject research set by the Belmont Report (My CITI training completion record ID is 31587963 ; the expiration date is November 7th, 2022).

\section{References}

Anderson, L. B., \& Gettings, P. E. (2020). Examining young adults' expectations for retirement: An emerging tension. Communication 
Studies, 71, 59-77. https://doi.org/10.1080/10510974.2019.16916 19

Archuleta, K. L., Dale, A., \& Spann, S. M. (2013). College students and financial distress: Exploring debt, financial satisfaction, and financial anxiety. Journal of Financial Counseling and Planning, $24,50-62$.

Beck, J. J., \& Garris, R. O. (2019). Managing personal finance literacy in the United States: A case study. Education Sciences, 9, 129. https://doi.org/10.3390/educsci9020129

Benartzi, S., \& Thaler, R. (2007). Heuristics and biases in retirement savings behavior. Journal of Economic Perspectives, 21, 81-104. https://doi.org/10.1257/jep.21.3.81

Benartzi, S., \& Thaler, R. H. (2013). Behavioral economics and the retirement savings crisis. Science, 339, 1152-1153. https://doi. org/10.1126/science. 1231320

Brown, M., Grigsby, J., van der Klaauw, W., Wen, J., \& Zafar, B. (2016). Financial education and the debt behavior of the young. The Review of Financial Studies, 29, 2490-2522. https://doi.org/ 10.1093/rfs/hhw006

Cohen, J. (1992). A power primer. Psychological Bulletin, 112, 155159. https://doi.org/10.1037/0033-2909.112.1.155

Council for Economic Education (2020). Economic and personal finance education in our nation's schools. Obtained from: https:// www.councilforeconed.org/wp-content/uploads/2020/02/2020Survey-of-the-States.pdf

Cumming, G. (2012). Understanding the new statistics: Effect sizes, confidence intervals, and meta-analysis. Routledge.

Fry, R., Pasel, J. S., \& Cohn, D. (2020). A majority of young adults in the U.S. live with their parents for the first time since the Great Depression. Pew Research Center. Retrieved from: https://www. pewresearch.org/fact-tank/2020/09/04/a-majority-of-youngadults-in-the-u-s-live-with-their-parents-for-the-first-time-sincethe-great-depression/

Gilbert, D. T., Gill, M. J., \& Wilson, T. D. (2002). The future is now: Temporal correction in affective forecasting. Organizational Behavior and Human Decision Processes, 88, 430-444. https:// doi.org/10.1006/obhd.2001.2982

Goel, S., Obeng, A., and Rothschild, D. (2015). Non-representative surveys: Fast, cheap, and mostly accurate. Working Paper. Retrieved from: https://researchdmr.com/FastCheapAccurate.pdf

Gudmunson, C. G., \& Danes, S. M. (2011). Family financial socialization: Theory and critical review. Journal of Family and Economic Issues, 32, 644-667. https://doi.org/10.1007/s10834-011-9275-y

Hancock, A. M., Jorgensen, B. L., \& Swanson, M. S. (2012). College students and credit card use: The role of parents, work experience, financial knowledge, and credit card attitudes. Journal of Family and Economic Issues, 34, 369-381. https://doi.org/10.1007/ s10834-012-9338-8

Harmon-Jones, E., \& Harmon-Jones, C. (2007). Cognitive dissonance theory after 50 years of development. Zeitschrift Für Sozialpsychologie, 38, 7-16. https://doi.org/10.1024/0044-3514.38.1.7

Hastings, J. S., Madrian, B. C., \& Skimmyhorn, W. L. (2013). Financial literacy, financial education, and economic outcomes. The Annual Review of Economics, 5, 347-373. https://doi.org/10.1146/annur ev-economics-082312-125807

Hershfield, H. E., Goldstein, D. G., Sharpe, W. F., Fox, J., Yeykelis, L., Carstensen, L. L., \& Bailenson, J. N. (2011). Increasing saving behavior through age-progressed renderings of the future self. Journal of Marketing Research, 48, 23-37. https://doi.org/10. 1509/jmkr.48.SPL.S23

Kaiser, T., \& Menkhoff, L. (2019). Financial education in schools: A meta-analysis of experimental studies. Economics of Education Review. https://doi.org/10.1016/j.econedurev.2019.101930

Kaiser, T., Lusardi, A., Menkhoff, L., \& Urban, C. J. (2020). Financial education affects financial knowledge and downstream behaviors.
NBER Working Paper 27057. Retrieved from: https://www.nber. org/papers/w27057.

Kraft, M. (2020). Interpreting Effect Sizes of Education Interventions. Educational Researcher, 49, 241-253. https://doi.org/10.3102/ 0013189X20912798

Krijnen, J. M. T., Zeelenberg, M., Breugelmans, S. M., \& van der Schors, A. (2018). Intention and action in retirement preparation. Behavioural Public Policy. https://doi.org/10.1017/bpp.2018.39

La Guardia, J. G., \& Patrick, H. (2008). Self-determination theory as a fundamental theory of close relationships. Canadian Psychology, 49, 201-209. https://doi.org/10.1037/a0012760

LeBaron, A. B., Holmes, E. K., Jorgensen, B. L., \& Bean, R. A. (2020). Parental financial education during childhood and financial behaviors of emerging adults. Journal of Financial Counseling and Planning, 31, 42-54. https://doi.org/10.1891/JFCP-18-00021

LeBaron, A. B., Runyan, S. D., Jorgensen, B. L., Marks, L. D., Li, X., \& Hill, E. J. (2019). Practice makes perfect: Experiential learning as a method for financial socialization. Journal of Family Issues, 40, 435-463. https://doi.org/10.1177/0192513X18812917

Litman, L., Robinson, J., \& Rosenzweig, C. (2015). The relationship between motivation, monetary compensation, and data quality among US- and India-based workers on Mechanical Turk. Behavior Research Methods, 47, 519-528. https://doi.org/10. 3758/s13428-014-0483-x

McCormick, M. H. (2009). The effectiveness of youth financial education: A review of the literature. Journal of Financial Counseling and Planning, 20, 70-83. Available at SSRN: https://ssrn.com/ abstract $=2225339$

Morrissey, M. (2019). Policy solutions for the retirement crisis. Generations: Journal of the American Society on Aging, 43, 98-104. Retrieved from: https://www.jstor.org/stable/26841740

Munnell, A. H., Hou, W. H., \& Sanzenbacher, G. T. (2018). National retirement risk index shows modest improvement in 2016. Retrieved from Center for Retirement Research at Boston College. Available at: https://crr.bc.edu/wp-content/uploads/2018/ 01/IB_18-1.pdf

Pew Research Center (2018). Nearly half of post-Millennials are racial or ethnic minorities. Obtained at: https://www.pewsocialtrends. org/2018/11/15/early-benchmarks-show-post-millennials-ontrack-to-be-most-diverse-best-educated-generation-yet/psdt-1115-18_postmillennials-00-00/

Petkoska, J., \& Earl, J. K. (2009). Understanding the influence of demographic and psychological variables on retirement planning. Psychology and Aging, 24, 245-251. https://doi.org/10.1037/a0014 096

Rusbult, C. E., Finkel, E. J., \& Kumashiro, M. (2009). The Michelangelo phenomenon. Current Directions in Psychological Science, 18, 305-309. https://doi.org/10.1111/j.1467-8721.2009.01657.x

Shapiro, G. K., \& Burchell, B. J. (2012). Measuring financial anxiety. Journal of Neuroscience, Psychology, and Economics, 5, 92-103. https://doi.org/10.1037/a0027647

Sheeran, P., \& Webb, T. L. (2016). The intention-behavior gap. Social and Personality Psychology Compass, 10, 503-518. https://doi. org/10.1111/spc3.12265

Sherraden, M. S., Johnson, L., Guo, B., \& Elliott, W. (2011). Financial capability in children: Effects of participation in a schoolbased financial education and savings program. Journal of Family and Economic Issues, 32, 385-399. https://doi.org/10.1007/ s10834-010-9220-5

Shim, S., Barber, B. L., Card, N. A., Xiao, J. J., \& Serido, J. (2010). Financial socialization of first-year college students: The roles of parents, work, and education. Journal of Youth and Adolescence, 39, 1457-1470. https://doi.org/10.1007/s10964-009-9432-x

Shim, S., Xiao, J. J., Barber, B. L., \& Lyons, A. C. (2009). Pathways to life success: A conceptual model of financial well-being for 
young adults. Journal of Applied Developmental Psychology, 30, 708-723. https://doi.org/10.1016/j.appdev.2009.02.003

Thaichon, P. (2017). Consumer socialization process: The role of age in children's online shopping behavior. Journal of Retailing and Consumer Services, 34, 38-47. https://doi.org/10.1016/j.jretc onser.2016.09.007

Thaler, R. H., \& Benartzi, S. (2004). Save More Tomorrow ${ }^{\mathrm{TM}}$ : Using behavioral economics to increase employee saving. Journal of Political Economy, 112, 164-187. https://doi.org/10.1086/380085

Vogel, E. A. (2020). From virtual parties to ordering food, how Americans are using the internet during COVID-19. Pew Research Center. Retrieved from: https://www.pewresearch.org/fact-tank/ 2020/04/30/from-virtual-parties-to-ordering-food-how-americansare-using-the-internet-during-covid-19/

Voorpostel, M., \& van der Lippe, T. (2007). Support between siblings and between friends: Two worlds apart? Journal of Marriage and Family, 69, 1271-1282. https://doi.org/10.1111/j.1741-3737.2007. 00446.x

Washington State Department of Financial Institutions (2020). Financial education resources for high school. Retrieved from: https:// dfi.wa.gov/financial-education/educators/high-school
Webley, P., \& Nyhus, E. K. (2006). Parents' influence on children's future orientation and saving. Journal of Economic Psychology, 27, 140-164. https://doi.org/10.1016/j.joep.2005.06.016

Wiedmer, T. (2015). Generations do differ: Best practices in leading traditionalists, boomers, and generations $\mathrm{X}, \mathrm{Y}$, and $\mathrm{Z}$. The Delta Kappa Gamma Bulletin, 82, 51-58.

Wiener, J., \& Doescher, T. (2008). A framework for promoting retirement savings. The Journal of Consumer Affairs, 42, 137-164. https://doi.org/10.1111/j.1745-6606.2008.00102.x

Publisher's Note Springer Nature remains neutral with regard to jurisdictional claims in published maps and institutional affiliations.

Stanislav Treger is a Senior Behavioral Scientist at Morningstar, Inc. His research focuses broadly on the psychology of retirement. 